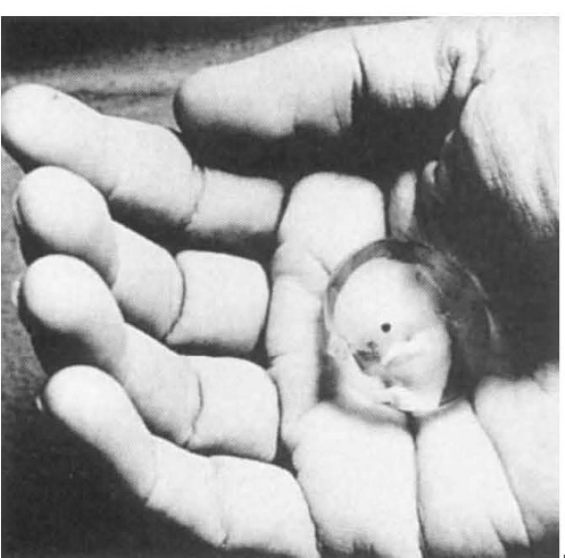

Eight-week human fetus in amniotic sac.

It is a pleasure to report that, on both counts, Zygote scores well. This quarterly contains articles that early embryologists will need to read, and that later ones may find useful. Its format is modern, its plates are well produced and it is fairly priced. Further, early issues contain a commentary or a review, while the editors have instituted a "Forum" where they hope that controversial areas will be discussed. It is still too soon to decide whether the contributors to these features can keep up their early momentum, but, even if they do run out of steam, Zygote has made a good start in attracting interesting papers, and will probably become necessary reading for workers in the field.

Jonathan Bard is in the Department of Anatomy, University of Edinburgh, Edinburgh EH8 9AG, UK.

\section{Nerve centres}

\section{Michael R. Hanley}

Clinical Neuroscience. Guest editors. Wiley-Liss. 4/yr. USA \$150, Canada and Mexico \$190, elsewhere \$205 (institutional); USA, Canada and Mexico $\$ 60$, elsewhere $£ 80$ (personal).

Neurobiology. Editor-in-chief N. Halász. Akadémiai Kiadó, Budapest. 4/yr. \$82.

THESE two journals are the latest entries into the now mature publishing market for neuroscience research. Clinical Neuroscience is a review journal, each issue dedicated to a specific theme, whereas Neurobiology intends to publish primary research, mixed with reviews and meeting abstracts. Clinical Neuroscience describes itself as "a new forum at the interface of the laboratory and clinic". The journal was launched in response to the increasing need for basic scientists to become aware of clinical applicability, and for clinicians to appreciate fundamental disease mechanisms. Existing journals in neurology or psychiatry do not satisfy these needs, because their historical emphasis
홍 has been on case studies and clinical experience, with modest attention to basic neurobiology. But newer journals are starting to bridge the gap between clinicians and basic scientists, albeit in different ways. For comparison, a comparable initiative is the clinically oriented series of Current Opinion titles, but these volumes are not dedicated to a single theme, and therefore lack the useful comprehensive quality of Clinical Neuroscience.

Clinical Neuroscience uses a format of $8-10$ short reviews commissioned by a guest editor on a specialist topic. So far, the journal has drawn topics from the obvious, but useful, menu of specific brain disorders, such as Alzheimer's disease or depression. Although the list of disorders in neurology and psychiatry is long, it will be a challenge to reinvigorate this way of organizing information. The risk here is the endless recycling of neurological diseases, stifling intellectual renewal of a journal of this type. Perhaps selecting topics that span a variety of diseases, such as novel therapeutic strategies or biological processes, will provide the needed change of pace.

On the whole, the journal is successful. The articles are concise, well written and well illustrated. The topics selected by each editor show a worthy balance between dogma and heresy, giving a balanced perception of controversies and ambiguities. This journal is worthwhile for libraries, but it is quite expensive for individuals, particularly as many of the topics are, in fact, fairly heavily reviewed elsewhere. Nevertheless, this venture has an original and useful vision of bridging the communities of basic and applied neuroscience.

Neurobiology, on the other hand, is an eccentric initiative in recommissioning an existing original research journal. The Hungarian Academy of Sciences has converted an earlier failed journal, Acta Biochimica et Biophysica Hungarica into an "international multidisciplinary journal in neurosciences". But the international character of the journal is more in the intent than the observance. Virtually all the published articles are from Hungarian laboratories. Moreover, the journal draws heavily from abstracts from Hungarian societies (of physiology and neuroscience, for example), symposia and so on. Overall, the contributions are fairly marginal and of limited interest. There is little more to say - this is a parochial journal, struggling to develop from an exclusively Hungarian base. In view of the stiff and excellent competition for publication of original articles in neurobiology, the journal is unlikely to make much of an impact, and it cannot really be recommended.

Michael R. Hanley is in the Department of Biological Chemistry, University of California School of Medicine, Davis, California 95616-8635, USA.

\section{Ins and outs}

William A. Catterall

Receptors and Channels. Editor-in-chief E. A. Barnard. Gordon and Breach. 4/vol. ECU382, $\$ 458$ (institutional); ECU90, $\$ 108$ (personal).

OVER the past decade, research on receptors, ion channels and transporters has flourished owing to a fortunate confluence of improved methods for purification and characterization of complex membrane proteins, convenient methods of cloning their genes and efficient expression systems for analysis of how they work. This flood of important advances has spread across the pages of Nature and many other journals. The volume of important work on these key cellular regulators has long justified the introduction of a new specialty journal focusing on their molecular and cellular properties. Receptors and Channels made its debut just over a year ago with the aim of filling this niche. It is off to an excellent start.

The senior editors provide a broad view from Europe, North America and Japan and cover the diversity of subject matter in this field with expertise in cellular and molecular biology, biophysics and electrophysiology. The international editorial board contains a wide range of acknowledged experts in the main areas of interest. Early issues contain noteworthy articles on potassium and chloride channels, inositol 1,4,5-trisphosphate receptors, $\mathrm{G}$ proteins, protein kinases, the multidrug transporter and a range of cellsurface receptors. As the field continues to expand, we can look to an increasingly important array of articles of interest to cell and molecular biologists, physiologists, pharmacologists and other biomedical researchers.

William A. Catterall is in the Department of Pharmacology, University of Washington, Seattle, Washington 98195, USA.

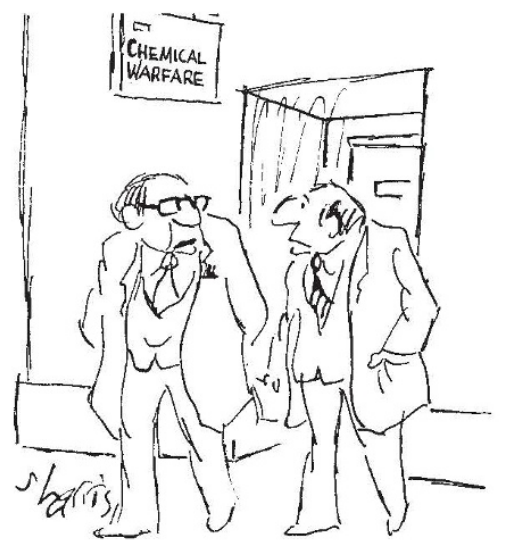

'IF ONLY THERE WERE SOME PEACEFUL USES FOR NERVE GAS." 